\title{
Soil-Building Interaction under Surface Horizontal Strain Induced by Underground Mining
}

\author{
Xiaopeng Liu $(\mathbb{D})$ and Liangji Xu \\ School of Spatial Informatics and Geomatics Engineering, Anhui University of Science and Technology, Huainan 232001, China \\ Correspondence should be addressed to Xiaopeng Liu; xp_liu001@163.com
}

Received 28 June 2021; Revised 9 December 2021; Accepted 13 December 2021; Published 22 January 2022

Academic Editor: Zhiguo Zhang

Copyright (C) 2022 Xiaopeng Liu and Liangji Xu. This is an open access article distributed under the Creative Commons Attribution License, which permits unrestricted use, distribution, and reproduction in any medium, provided the original work is properly cited.

\begin{abstract}
Underground mining causes the ground to deform, leading to the destruction of buildings. Horizontal strain is one of the most important causes of damage to strip foundation buildings. However, related research is insufficient and the mechanism behind building damage caused by horizontal strain remains unclear, resulting in several difficulties in performing coal mining under villages. In this study, interface slip and soil pressure caused by the horizontal strain of ground transfer between soil and buildings are investigated, and stress concentration in buildings driven by soil movement is considered the primary cause of building damage. The influences of the mechanical parameters of soil and the geometric parameters of a building on stress distribution inside a building are analyzed by establishing a stress distribution model of a building under different ground horizontal strains. Softening the foundation or designing deformation joints inside a building can reduce the influence of horizontal strain on a building. This research can provide an important reference for performing coal mining safely under villages and designing building protection against ground horizontal strain.
\end{abstract}

\section{Introduction}

As one of the most important energy sources, coal will still be utilized on a large scale in the next few decades. However, ground movement and deformation caused by underground coal mining result in damages to adjacent buildings and endanger the safety of properties and residents $[1,2]$. Although ground movement can be reduced via filling mining, strip mining, and harmonic mining, understanding how ground deformation acts on buildings and the interaction between ground deformation and building damage will promote the development of a coal mining technology that can be performed safely under villages and a building protection technology against surface movement and deformation [3].

In addition to coal mining, other causes of surface movement deformation include tunnel excavation and groundwater overexploitation. Surface movement deformations caused by the aforementioned reasons interact with the structure of a building, threatening the safe use of this building. On the basis of a research on soil-structure interaction under the influence of tunnel excavation, Basmaji et al. [4] established a predictive model of structural bending caused by soil movement to study the effect of tunnel excavation on surface buildings. After studying the correlation between tunnel excavation that leads to structural deformation and tunnel site conditions via discrete metasimulation, Son [5] proposed a new method for evaluating the relationship between tunnel depth diameter ratio and building damage level. To solve the problem of uncertainty of building damage caused by tunnel excavation, Fu et al. [6] developed a method based on the displacement relationship between soil and buildings. This method can be used to analyze the damage of a building by applying probability estimation to construction. Ou et al. [7] used the potential index of damage to assess the extent of damage to a building. In accordance with a numerical analysis, they proposed a predictive method for tunnel excavation that causes the deformation of surface movement. 
In the study on the effect of underground coal mining on buildings, the results have focused on the assessment of the extent of damage to buildings caused by coal mining [8-10]. By contrast, less research has been conducted on the mechanism behind the interaction of soil structures during surface movement deformation [11].

Some scholars also believe that surface subsidence caused by water extraction also exert a certain effect on buildings. Kadiyan et al. [12] investigated the characteristics of ground subsidence caused by underground water depletion and then analyzed the characteristics of house damage caused by different subsidence rates.

In addition, some scholars assert that the deformation of surface movement due to various reasons can be considered uniformly for the action mechanism of buildings. Eeka et al. [13] reported that surface movement rate affects damage to a building and used the modified Winkler-Pasternak elastic models and numerical simulations to assess the effect of different surface movement rates on a structure. El Kahi et al. [14] analyzed soil-structure interaction caused by surface curvature deformation on the basis of the Winkler and Euler-Bernoulli beam models. The authors also examined building damage caused by structural heterogeneity. Moosazadeh et al. [15] applied an artificial neural network model and the particle swarm optimization algorithm to predict damage to buildings caused by surface deformation.

At present, many studies have been conducted on the effect of surface movement deformation caused by tunnel excavation on buildings, but research on the damage mechanism of coal mining to surface buildings remains scarce. The tunnel excavation process frequently requires extremely safe support measures, and thus, the resulting surface deformation is often very small. In the coal mining process, the top plate of the mining area generally does not use any support measures. Even with certain rock formation control mining methods, such as filling mining and strip mining, surface subsidence is frequently greater than $200 \mathrm{~mm}$. Therefore, the research results of tunnel excavations cannot be applied directly to damage caused by coal mining. Simultaneously, most buildings in coal mining areas in rural regions are mostly single-story bar-based buildings, which are vulnerable to the effects of surface bending deformation and horizontal deformation caused by damage. At present, research results on soil-structure synergy under surface bending deformation [16] are numerous, posing some obstacles to the damage protection of buildings under horizontal deformation.

The current study investigates the interaction mechanism between soil and walls on the basis of the characteristics of surface horizontal strain caused by underground coal mining. Then, it clarifies the internal stress accumulation characteristics of buildings under different soil mechanics characteristics, building characteristics, and horizontal strains, and thus, it identifies the destruction law and mechanism of buildings under surface horizontal strain. Lastly, it proposes protection methods for buildings under horizontal strain. This research can provide an important reference for conducting coal mining under villages and designing building protection strategies.

\section{Characteristics of Ground Horizontal Strain Caused by Coal Mining}

After coal is mined underground, a subsidence basin with an area that is considerably larger than the mining area will form on the ground. During subsidence, the surface will move to the center of the subsidence basin. A horizontal strain will form on the surface as shown in Figure 1 because the amount of movement varies at different positions. Compressive deformation will occur on the corresponding surface of the goaf (the deformation sign is + ), while tensile deformation will occur on the side of the coal wall (the deformation sign is -).

The horizontal strain between two points on a surface can be obtained using the following formula by monitoring surface horizontal displacement:

$$
e=\frac{u_{i+1}-u_{i}}{l_{i \sim i+1}}
$$

where $e$ is the horizontal strain between two points on a surface, $u_{i}$ is the horizontal displacement of the $i$ th point, $u_{i}+1$ is the horizontal displacement of the $(i+1)$ th point, and $l_{i \sim i+1}$ is the horizontal distance between the $i$ th and $(i+1)$ th monitoring points.

In China, the probability integral method is the leading strategy for mining subsidence prediction [17, 18]. The principle of the aforementioned method is to regard rock formations broken by mining as random particles that are not related to one another. The particle medium is unaffected by particle size and the geometry of formations under the influence of gravity, but instead, it is only governed by random laws. The expected principle model of surface subsidence caused by unit mining is shown in Figure 2.

The formula for surface subsidence caused by unit mining is obtained through the principle of random media as follows:

$$
W_{e}(x)=\frac{1}{r} e^{-\pi x^{2} / r^{2}},
$$

where $W$ is the surface subsidence and $r$ is the primary influence radius.

By integrating surface subsidence caused by unit mining, the estimated formula for surface subsidence caused by limited-range mining of the working surface is obtained as follows:

$$
W(x)=m q \cos a \frac{1}{\sqrt{\pi}}\left(\int_{0}^{x \sqrt{\pi} / r} e^{-s^{2}} \mathrm{~d} s-\int_{0}^{(x-S) \sqrt{\pi} / r} e^{-s^{2}} \mathrm{~d} s\right),
$$

where $m$ is the mining height, $a$ is the coal seam dip, $q$ is the subsidence coefficient, and $s$ is the working face length.

In accordance with the theory of isometric volume of deformed bodies, surface horizontal displacement $U$ is related to subsidence, and its calculation formula is

$$
U(x)=b r \frac{\partial W(x)}{\partial x} .
$$




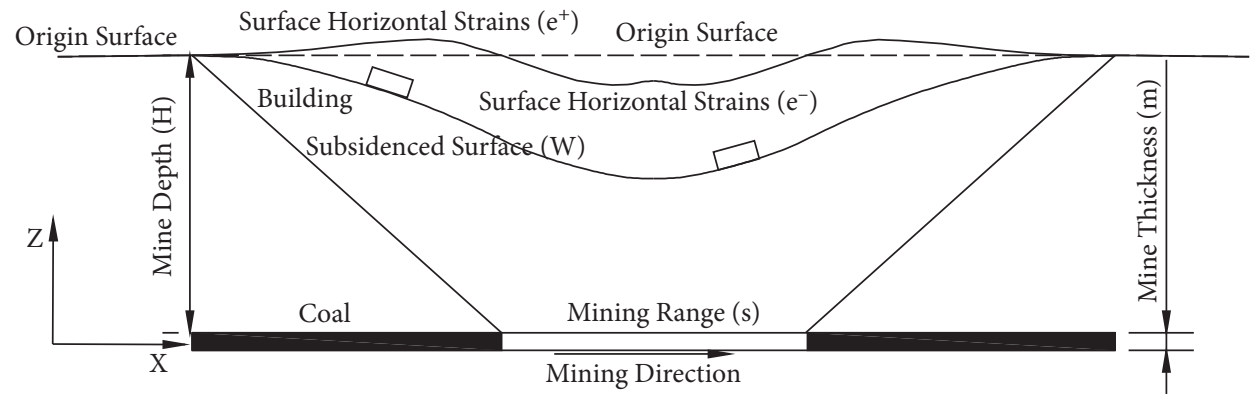

FIGURE 1: Sketch map of surface horizontal strain.
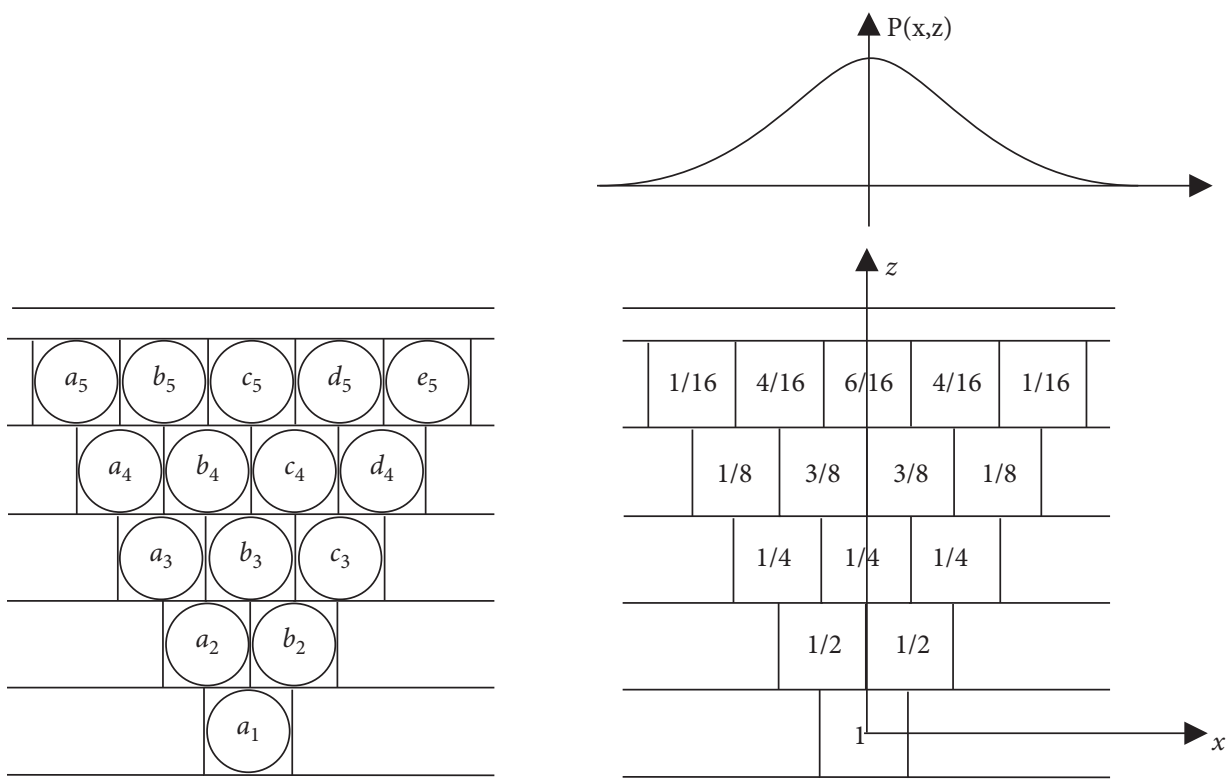

Figure 2: Schematic of random media theory. is

The prediction formula for the surface horizontal strain $e$

$$
e(x)=\frac{\partial U(x)}{\partial x}
$$

\section{Interaction between the Building Foundation and the Soil}

Relative movement occurs between the building foundation and the soil under the action of surface horizontal strain. This movement generates additional horizontal stress in the building foundation, resulting in the tensile or compressive damage of the building.

Relative movement between the building foundation and the soil exerts two major effects on the building foundation: (a) the slipping effect of interface movement between the soil and the building foundation and (b) the lateral pressure produced by mutual extrusion between the soil and the building foundation.
3.1. Interface Slip between the Soil and the Building Foundation. In accordance with one study, the contact relationship between rock and soil interfaces satisfies Mohr-Coulomb's law, and this constitutive relation is presented in Figure 3.

When the interface is in elastic state, the tangential force between the building foundation and the soil is positively correlated with relative displacement.

$$
F_{s}=k_{s} u_{s}
$$

where $k_{s}$ is the shear stiffness of the interface and $u_{s}$ is the relative displacement between the building foundation and the soil.

In accordance with Coulomb's shear strength criterion, the interface is destroyed once the interface tangential force reaches the maximum value that it can bear.

$$
F_{\text {smax }}=c+F_{n} \tan \varphi \text {. }
$$

Only residual friction remains between the interfaces after the interface is damaged. At this point, the interface 


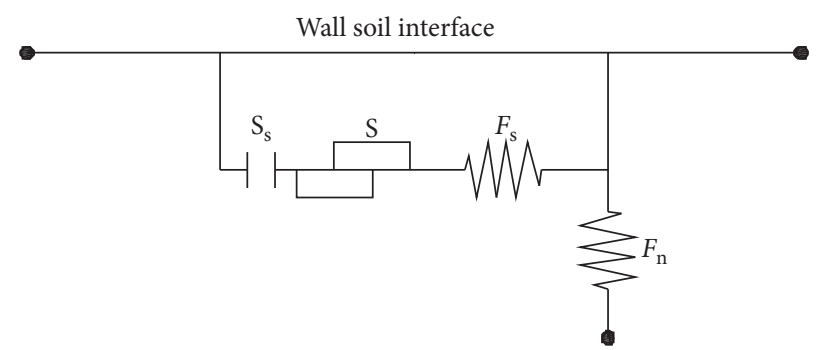

Figure 3: Constitutive model of interfacial slip $\left(F_{n}\right.$ is the directional force, $F_{s}$ is the tangent force, $S$ is the slider, and $S_{s}$ is the tangent module).

tangential force is

$$
F_{s}=F_{n} \tan \varphi
$$

3.2. Lateral Pressure of Soil. When horizontal strain occurs on the surface, relative motion is produced between the building foundation and the soil, and the soil is transformed from a static state into an active or passive state. When surface deformation is tensile, the soil inside the building is in passive state, whereas the soil outside the building is in active state. When surface deformation is compressed, the soil inside the building is in active state, while the soil outside the building is in passive state. At this moment, the force on both sides of the foundation is no longer balanced, exerting tensile and compressive effects on a building.

Terzaghi et al. [19], Xie et al. [20], and Wilson [21] regarded wedges $\mathrm{ABC}$ and $\mathrm{A}^{\prime} \mathrm{B}^{\prime} \mathrm{C}^{\prime}$ in Figure 3 as rigid bodies that only produce displacement but do not deform. When the shear deformation per unit length of slip surfaces $\mathrm{AC}$ and $\mathrm{A}^{\prime} \mathrm{C}^{\prime}$ reaches the limit state, soil reaches the limit equilibrium state. At this moment, Earth pressure on the wall is active or passive.

Active Earth pressure state: as shown in Figure 4, when the wall moves away from the soil, wedge ABC slides into the same direction and wall pressure enters an active state. In such case, the relationship between the lateral displacements of the wall $U_{a}$ and the shear deformation of the slip surface $\varepsilon_{1}$ is as follows:

$$
\frac{U_{a}}{H}=\varepsilon_{1} \tan \left[45^{\circ}-\frac{\varphi}{2}\right]
$$

where $\varphi$ is the internal friction angle of the soil and $H$ is the depth of foundation buried in the soil.

In accordance with the principle of limit equilibrium, the critical depth of active Earth pressure $z$ is

$$
z=\frac{2 c}{\gamma \tan \left(45^{\circ}-\varphi / 2\right)},
$$

where $\gamma$ is the bulk density of soil.

When the shear deformation of soil $\varepsilon_{1}$ increases from 0 to the ultimate shear strain $\varepsilon_{\max }$, the pressure formed between the soil and the wall transforms from static into active Earth pressure. Assuming that the stress-strain relationship in this process exhibits a straight line, the relationship between wall lateral pressure $P_{a}^{\prime}$ and wall lateral displacement in an active state is as follows.

When $H<z$,

$P_{a}^{\prime}= \begin{cases}\frac{-U_{a} P_{0}}{\varepsilon_{\max } H \tan \left(45^{\circ}-\varphi / 2\right)}+P_{0}, & U_{a}<H \varepsilon_{\max } \tan \left[45^{\circ}-\frac{\varphi}{2}\right], \\ 0, & U_{a} \geq H \varepsilon_{\max } \tan \left[45^{\circ}-\frac{\varphi}{2}\right] .\end{cases}$

When $H \geq z$,

$P_{a}^{\prime}= \begin{cases}\frac{U_{a}\left(P_{a}-P_{0}\right)}{\varepsilon_{\max } H \tan \left(45^{\circ}-\varphi / 2\right)}+P_{0}, & U_{a}<H \varepsilon_{\max } \tan \left[45^{\circ}-\frac{\varphi}{2}\right], \\ P_{a}, & U_{a} \geq H \varepsilon_{\max } \tan \left[45^{\circ}-\frac{\varphi}{2}\right],\end{cases}$

where $P_{a}^{\prime}$ is the total active Earth pressure and $P_{0}$ is the static Earth pressure.

$$
\begin{aligned}
& P_{a}=\frac{1}{2} \gamma H^{2} \tan ^{2}\left(\frac{45^{\circ}-\varphi}{2}\right)-2 c H \tan \left(\frac{45^{\circ}-\varphi}{2}\right)+\frac{2 c^{2}}{\gamma}, \\
& P_{0}=\frac{1}{2} \gamma H^{2}(1-\sin \varphi) .
\end{aligned}
$$

Passive Earth pressure state: as shown in Figure 4, when the wall produces lateral displacement that towards the soil, wedge $\mathrm{A}^{\prime} \mathrm{B}^{\prime} \mathrm{C}^{\prime}$ moves along with it and the wall enters a passive state. In such case, the relationship between the lateral displacement of the wall $U_{p}$ and the shear deformation of the slip surface $\varepsilon_{1}$ is as follows:

$$
\frac{U_{p}}{H}=\varepsilon_{1} \tan \left[45^{\circ}+\frac{\varphi}{2}\right] \text {. }
$$

When shear surface deformation $\varepsilon_{1}$ increases from 0 to the ultimate shear strain $\varepsilon_{\max }$, the pressure between the soil and the wall transforms from static into passive Earth pressure. Assuming that the stress-strain relationship in this process is a straight line, the relationship between wall lateral pressure $P_{a}^{\prime}$ and wall lateral displacement in passive state is as follows: 


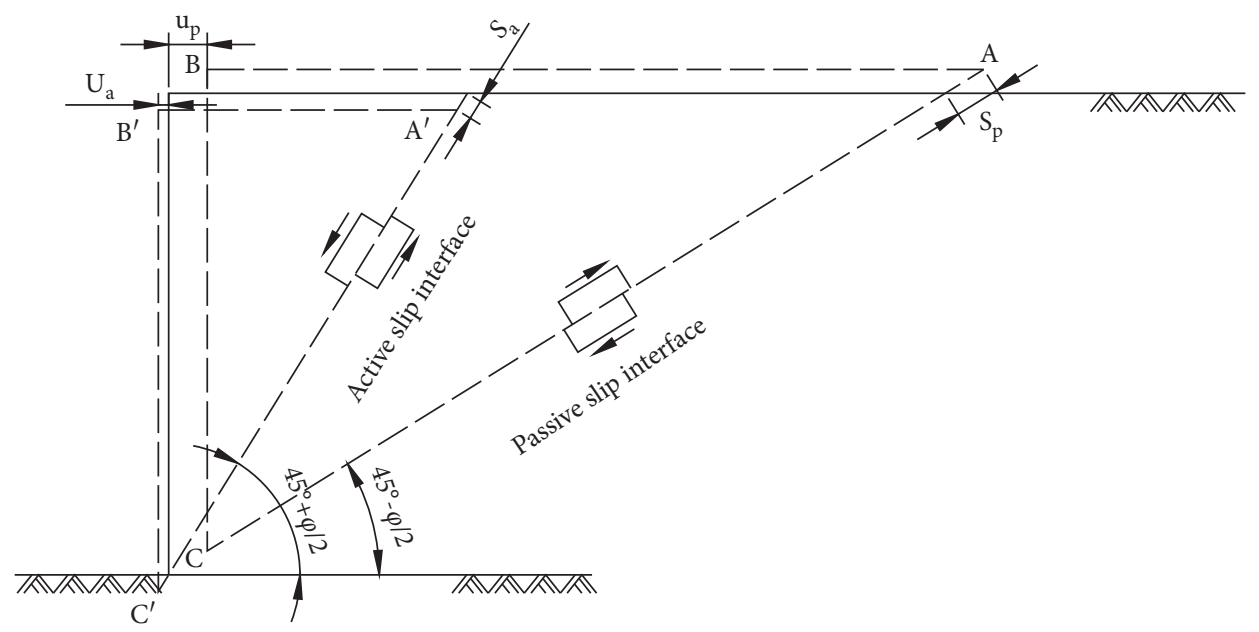

Figure 4: Diagram of Earth pressure under active or passive conditions.

$$
\begin{aligned}
& P_{p}^{\prime}= \begin{cases}\frac{U_{p}\left(P_{p}-P_{0}\right)}{\varepsilon_{\max } H \tan \left(45^{\circ}+\varphi / 2\right)}, & U_{p}<H \varepsilon_{\max } \tan \left[45^{\circ}+\frac{\varphi}{2}\right], \\
P_{p}, & U_{p} \geq H \varepsilon_{\max } \tan \left[45^{\circ}+\frac{\varphi}{2}\right],\end{cases} \\
& P_{p}=\frac{1}{2} \gamma H^{2} \tan ^{2}\left(\frac{45^{\circ}+\varphi}{2}\right)+2 c H \tan \left(\frac{45^{\circ}+\varphi}{2}\right),
\end{aligned}
$$

where $P_{p}^{\prime}$ is the total passive Earth pressure.

\section{Analysis of Additional Stress in Buildings under Surface Horizontal Strain}

Compared with the entire mining subsidence basin, a single bungalow is typically extremely small, and thus, the surface horizontal strain value near each house can be considered consistent. Assuming that the surface horizontal strain direction is parallel to the longitudinal wall, the soil at the center of the building does not move and surface movement increases gradually from the center toward both ends of the building's longitudinal wall. The tension and compression caused by surface horizontal strain mostly act on the longitudinal wall of the building.

A bungalow is simplified as a frame that consists of two transverse walls and two longitudinal walls. The coordinate system is established with the center of the building as the origin point, as shown in Figure 5. Half of the longitudinal and transverse walls of the building can be analyzed because the stress of the building is symmetric around the coordinate axis. Three additional stresses are caused by interface sliding between building foundation and soil (Figure 6): (a) the slip contact force between the side of the longitudinal wall foundation and the soil is $F_{s}{ }^{1}$, (b) the slip contact force between the bottom of the longitudinal wall foundation and the soil is $F_{s}^{2}$, and (c) the slip contact force between the bottom of the transverse wall foundation and the soil is $F_{s}^{3}$.
The lateral pressure between the building foundation and the soil is active and passive Earth pressure $\left(P_{a}^{\prime} / P_{b}^{\prime}\right)$ is on both sides of the transverse wall foundation.

Assuming that the surface horizontal strain is $e$ and the length of the longitudinal wall is $l_{x}$, the relative displacement between the longitudinal wall foundation's coordinate $x$ and the soil is

$$
u_{x}(x)=e x
$$

The relative displacement between the transverse wall foundation and the soil is as follows:

$$
u^{\prime}=e \frac{l_{x}}{2}
$$

In such case, the horizontal force produced by the relative sliding between the side of the longitudinal wall foundation at coordinate $x$ and the soil is as follows:

$$
F_{s}^{1}(x)= \begin{cases}k_{s} e x, & x \leq \frac{c+s_{n}^{1} \tan \varphi}{e k_{s}}, \\ s_{n}^{1} \tan \varphi, & x>\frac{c+s_{n}^{1} \tan \varphi}{e k_{s}}\end{cases}
$$

where $s_{n}^{1}$ is the static Earth pressure. Assuming that the static Earth pressure is uniformly distributed along the vertical direction, then 


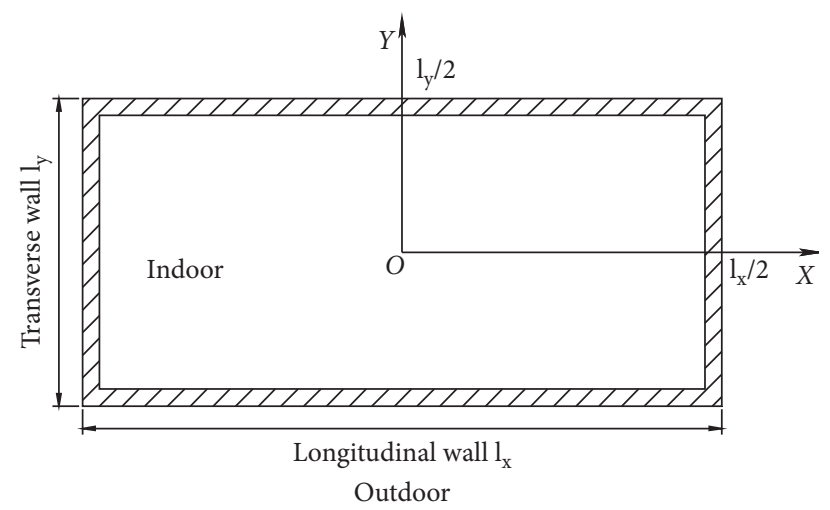

FiguRE 5: Plane and coordinate system diagram of a bungalow $\left(l_{x}\right.$ is the length of the longitudinal wall, and $l_{y}$ is the length of the transverse wall).

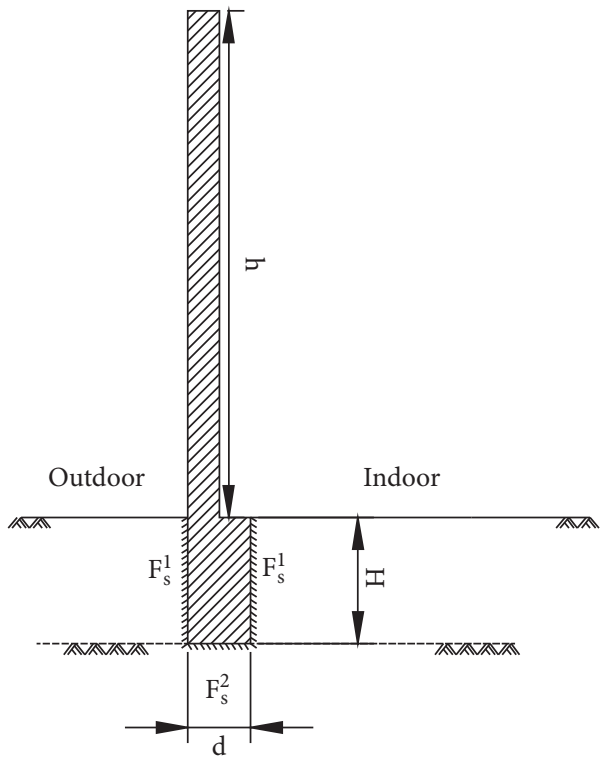

(a)

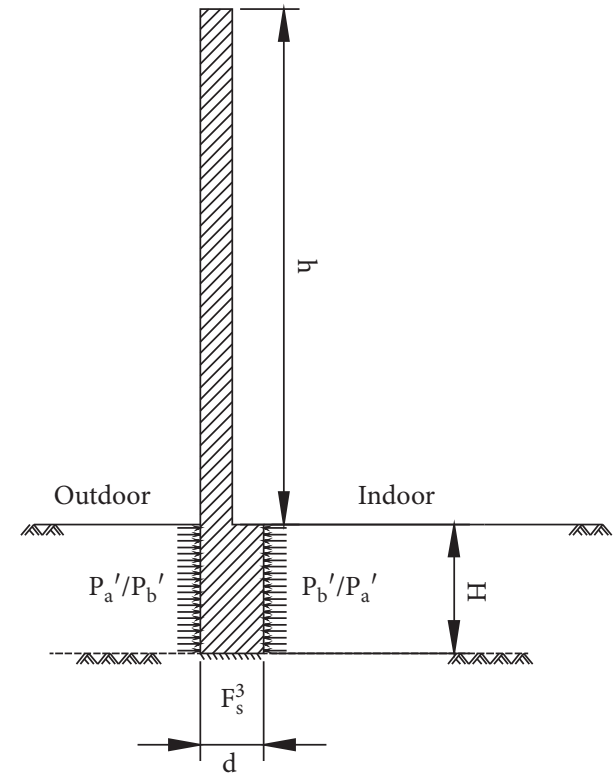

(b)

Figure 6: Vertical view of the wall. (a) Longitudinal wall. (b) Transverse wall. ( $F_{s}^{1}$ is the friction between the surface of the foundation side of the building and the foundation soil, $F_{S}{ }^{2}$ is the friction between the surface and the foundation soil under the foundation of the building, $P_{a}^{\prime}$ is the total active soil pressure, $P_{b}^{\prime}$ is the total passive soil pressure, $h$ is the wall height, and $H$ is the base height).

$$
s_{n}^{1}=\frac{1}{2} \gamma H(1-\sin \varphi)
$$

The additional horizontal stress produced by the slip action between the side of the longitudinal wall foundation and the soil at coordinate $x$ is as follows:

$$
\sigma_{1}(x)=2 \int_{x}^{l_{x} / 2} \frac{F_{s}^{1}(t)}{d} \mathrm{~d} t,
$$

where $d$ is the foundation thickness.

The horizontal force produced by the slip action between the bottom of the longitudinal wall foundation and the soil at coordinate $x$ is as follows:

$$
\begin{aligned}
& F_{s}^{2}(x)= \begin{cases}k_{s} e x, & x \leq \frac{c+s_{n}^{2} \tan \varphi}{e x}, \\
s_{n}^{2} \tan \varphi, & x>\frac{c+s_{n}^{2} \tan \varphi}{e x},\end{cases} \\
& s_{n}^{2}=\gamma(H+h),
\end{aligned}
$$

where $s_{n}^{2}$ is the foundation bottom pressure, $H$ is the foundation height, and $h$ is the wall height.

The additional horizontal stress caused by the slip action between the bottom of the longitudinal wall foundation and the soil at coordinate $x$ is as follows: 


$$
\sigma_{2}(x)=\int_{x}^{l_{x} / 2} \frac{F_{s}^{2}(t)}{d H} \mathrm{~d} t .
$$

The horizontal force produced by the relative sliding between the bottom of the transverse wall foundation and the soil is as follows:

$$
F_{s}^{3}= \begin{cases}k_{s} e \frac{l_{x}}{2}, & \frac{l_{x}}{2} \leq \frac{c+s_{n}^{2} \tan \varphi}{e x}, \\ s_{n}^{2} \tan \varphi, & \frac{l_{x}}{2}>\frac{c+s_{n}^{2} \tan \varphi}{e x} .\end{cases}
$$

The additional horizontal stress of the longitudinal wall caused by the relative slip between the bottom of the transverse wall foundation and the soil is as follows:

$$
\sigma_{3}=\frac{F_{s}^{3} l_{y}}{2 d H} \text {. }
$$

When the horizontal strain parallel to the longitudinal wall occurs on the ground surface, the soil at one side of the building's transverse wall foundation is in active state, whereas the soil at the other side is in a passive state. The lateral pressure generated by the soil in active state is as follows:

$P_{a}^{\prime}= \begin{cases}\frac{e l_{x} / 2\left(P_{a}-P_{0}\right)}{\varepsilon_{\max } H \tan \left(45^{\circ}-\varphi / 2\right)}, & e \frac{l_{x}}{2}<H \varepsilon_{\max } \tan \left[45^{\circ}-\frac{\varphi}{2}\right], \\ P_{a}, & e \frac{l_{x}}{2} \geq H \varepsilon_{\max } \tan \left[45^{\circ}-\frac{\varphi}{2}\right] .\end{cases}$

The lateral pressure produced by the soil in passive state is as follows:

$P_{b}^{\prime}= \begin{cases}\frac{e l_{x} / 2\left(P_{b}-P_{0}\right)}{\varepsilon_{\max } H \tan \left(45^{\circ}+\varphi / 2\right)}, & e \frac{l_{x}}{2}<H \varepsilon_{\max } \tan \left[45^{\circ}+\frac{\varphi}{2}\right], \\ P_{b}, & e \frac{l_{x}}{2} \geq H \varepsilon_{\max } \tan \left[45^{\circ}+\frac{\varphi}{2}\right] .\end{cases}$

The horizontal stress acting on the longitudinal wall through the combined forces on both sides of the transverse wall is as follows:

$$
\sigma_{4}=\frac{\left(P_{b}^{1}-P_{a}^{\prime}\right) l_{y} / 2}{d H} .
$$

At this moment, the horizontal stress in each part of the longitudinal wall foundation is as follows:

$$
\sigma(x)=\sigma_{1}(x)+\sigma_{2}(x)+\sigma_{3}+\sigma_{4} .
$$

\section{Results}

5.1. Stress Distribution inside the Foundation. On the basis of the soil experiment conducted by Wilson [21], the internal cohesion is $14 \mathrm{kPa}$, the internal friction angle is $44^{\circ}$, the shear modulus is $1.07 \mathrm{MPa}$, the ultimate shear strain is $1 \%$, and the interface reduction factor is 0.5 . In accordance with the general situation of rural bungalows in China, the building foundation height is $1 \mathrm{~m}$, the wall height is $4 \mathrm{~m}$, the bulk density is $20 \mathrm{kN}$, the longitudinal wall length is $20 \mathrm{~m}$, the transverse wall length is $6 \mathrm{~m}$, and the surface horizontal strain is $4 \mathrm{~mm} / \mathrm{m}$. The soil mechanical parameters are provided in Table 1.

By applying the theory in Section 4, the distribution of additional horizontal stress in the longitudinal wall foundation of a building under the aforementioned conditions is plotted in Figure 7. The horizontal stress at the middle of the longitudinal wall foundation is the greatest under the action of surface horizontal strain, and it gradually decreases from the middle to both sides of the foundation. Stress changes abruptly at coordinate $4.4 \mathrm{~m}$ because the interface between the side of the longitudinal wall foundation and the soil changes from an elastic state into a plastic state.

Considering that the additional horizontal stress at the middle of the longitudinal wall foundation is the greatest and most vulnerable to damage, the variation law of the additional horizontal stress at the middle of the longitudinal wall foundation with a horizontal strain value is analyzed. As shown in Figure 8, the additional horizontal stress at the middle of the longitudinal wall foundation increases with an increase in surface horizontal strain value and stress changes abruptly at B and C. After the abrupt change, the increment rate of extreme stress value decreases gradually. The sudden change at $B$ is due to the soil at the transverse wall foundation achieving passive Earth pressure, and thus, the lateral pressure $\sigma_{4}$ of the transverse wall foundation no longer increases.

The sudden change at $\mathrm{C}$ is caused by the wall-soil interface at the bottom of the transverse wall foundation achieving a plastic state and the sudden decrease in $\sigma_{3}$. Thereafter, the change rate of additional horizontal stress decreases sharply with the horizontal strain value. Therefore, we can use point $\mathrm{C}$ as the ultimate horizontal strain and the horizontal stress at point $\mathrm{C}$ is the ultimate additional stress. At this moment, the ultimate horizontal strain is approximately $9 \mathrm{~mm} / \mathrm{m}$ and the ultimate additional stress is $1.23 \mathrm{MPa}$.

\subsection{Stress Distribution in Buildings under Different Factors.} In accordance with the preceding analysis, the major factors that affect the relationship between the horizontal strain value and the additional stress state are the mechanical properties of the foundation soil (i.e., shear modulus, internal friction angle, cohesion, and ultimate shear strain), the mechanical properties of the interface (i.e., reduction coefficient of the interface), and the characteristics of the building (i.e., length of the transverse and longitudinal walls).

5.2.1. Soil Shear Modulus. As shown in Figure 9(a), soil shear modulus increases when surface horizontal strain remains unchanged, and the additional stress inside the 
TABLE 1: Soil mechanical parameters.

\begin{tabular}{lcccc}
\hline Internal cohesion $(\mathrm{kPa})$ & Internal friction angle & Shear modulus $(\mathrm{MPa})$ & Ultimate shear strain $(\%)$ & Interface reduction factor \\
\hline 14 & $44^{\circ}$ & 1.07 & 1 & 0.5 \\
\hline
\end{tabular}

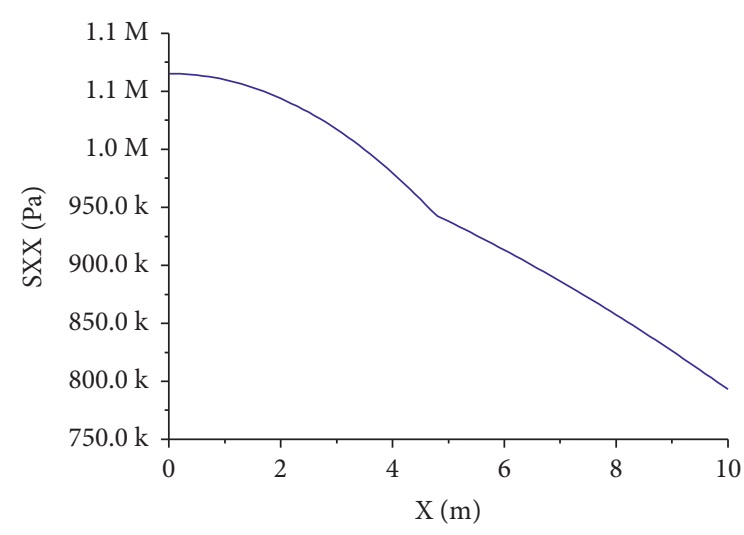

FIGURE 7: Distribution of horizontal stress along the longitudinal wall.

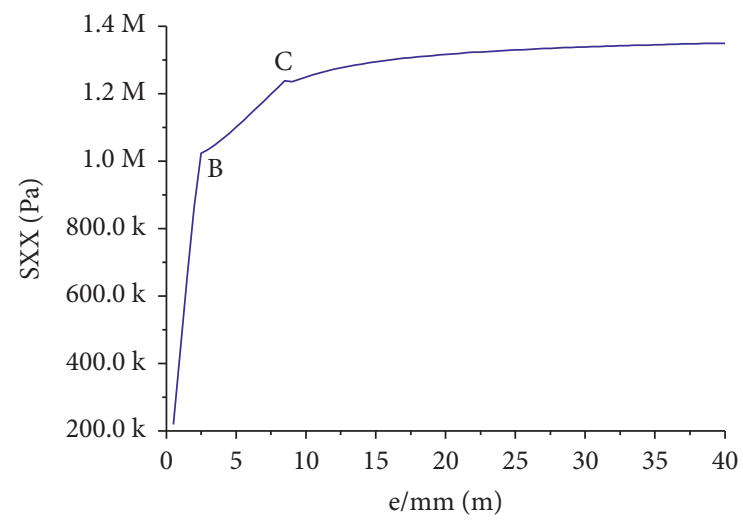

FIGURE 8: Variation of additional horizontal stress with horizontal strain at the middle of the longitudinal wall foundation.

building also increases. The shear modulus of the soil does not affect the extreme value of the additional stress. The additional horizontal stress converges steadily to approximately $1.24 \mathrm{MPa}$ with an increase in the horizontal strain value of the surface. The ultimate horizontal strain decreases from $13.5 \mathrm{~mm} / \mathrm{m}$ to $6 \mathrm{~mm} / \mathrm{m}$ when the shear modulus of the soil increases from $0.6 \mathrm{MPa}$ to $1.5 \mathrm{MPa}$. A conclusion can be drawn that the larger the shear modulus of the soil, the more vulnerable the building is to surface horizontal strain. However, when surface deformation is sufficiently large, the shear modulus of the soil exerts minimal effect on the additional stress inside the building foundation.

5.2.2. Soil Ultimate Shear Strain. Figure 9(b) shows that with an increase in the ultimate shear strain of the soil, additional stress in the building decreases gradually when surface horizontal strain remains unchanged. When lateral pressure reaches passive Earth pressure due to the relative movement of the transverse wall foundation and the soil, additional stress reaches the extreme stress value of $1.22 \mathrm{MPa}$, and the ultimate horizontal strain remains at $8 \mathrm{~mm} / \mathrm{m}$. Therefore, when surface horizontal strain is small, the smaller the ultimate shear deformation of the soil, the easier it will cause damage to a building. When surface horizontal strain is sufficiently large, the ultimate shear strain of the soil exerts minimal effect on the additional stress inside the building foundation.

5.2.3. Soil Cohesion. Under the same horizontal strain of the surface, additional stress in the building increases linearly with an increase in soil cohesion. However, an increase in soil cohesion exerts minimal effect on the ultimate surface horizontal strain. When cohesion is $6 \mathrm{kPa}$, the ultimate horizontal strain is $8 \mathrm{~mm} / \mathrm{m}$ and the ultimate additional stress is $1 \mathrm{MPa}$. When cohesion increases to $16 \mathrm{kPa}$, the ultimate horizontal strain increases to only $9 \mathrm{~mm} / \mathrm{m}$ and the ultimate horizontal stress increases to 1.3 MPa (Figure 9(c)). In general, under the same surface horizontal strain, the greater the cohesion of the soil, the more likely it is to cause damage to buildings.

5.2.4. Friction Angle in the Soil. When surface horizontal strain is less than $1.5 \mathrm{~mm} / \mathrm{m}$, additional horizontal stress in the building foundation hardly changes with a change in friction angle in the soil. When surface horizontal strain is greater than $1.5 \mathrm{~mm} / \mathrm{m}$, the additional stress in the foundation increases sharply with increasing internal friction angle. Simultaneously, the ultimate horizontal strain increases with an increase in friction angle. When the internal friction angle is $20^{\circ}$, the extreme value of horizontal strain is $4.5 \mathrm{~mm} / \mathrm{m}$ and that of the additional stress is $0.65 \mathrm{MPa}$. When the internal friction angle reaches $45^{\circ}$, the extreme value of horizontal strain is $10 \mathrm{~mm} / \mathrm{m}$ and that of stress is 1.5 MPa (Figure 9(d)). A conclusion can be drawn that an increase in friction angle in the soil can considerably affect the damage degree of buildings under surface horizontal strain.

5.2.5. Interface Reduction Coefficient. The smoothness of the foundation wall exerts a remarkable influence on the mechanical properties of the interface, affecting the effect of surface horizontal strain on the building. As shown in Figure 9(e), additional horizontal stress increases with an increase in the interface reduction coefficient when the horizontal strain of the surface remains unchanged. When the reduction coefficient is 0.3 , the extreme value of horizontal strain is $8 \mathrm{~mm} / \mathrm{m}$ and that of the additional stress is $1 \mathrm{MPa}$. When the reduction coefficient increases to 0.8 , the extreme value of horizontal strain is $9 \mathrm{~mm} / \mathrm{m}$ and that of the additional stress is $1.6 \mathrm{MPa}$. That is, the smoother the 


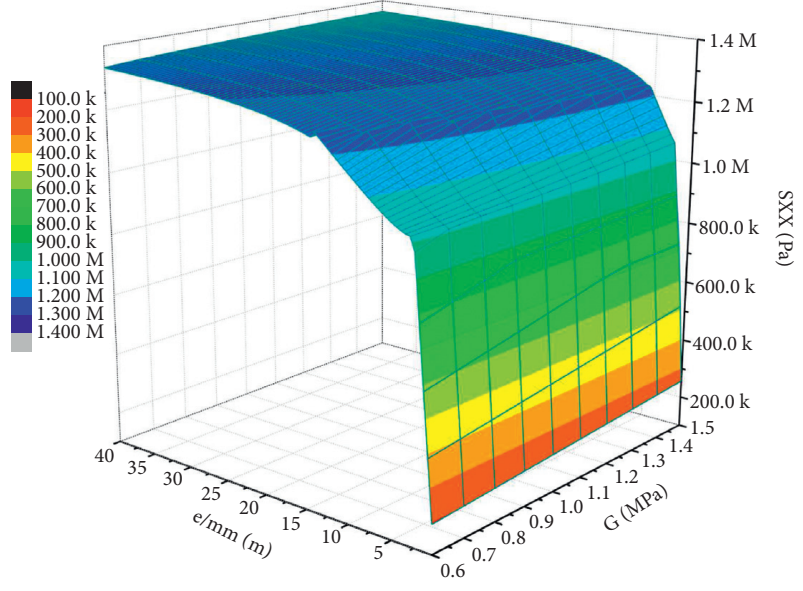

(a)

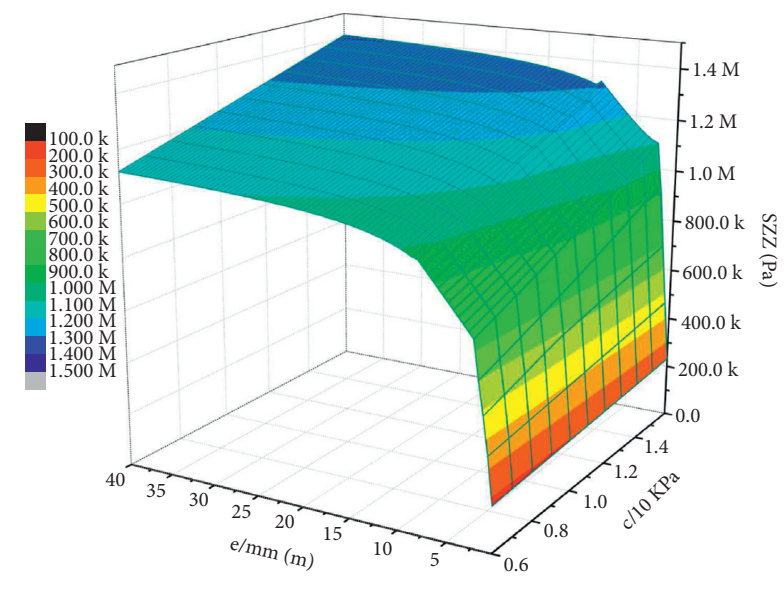

(c)

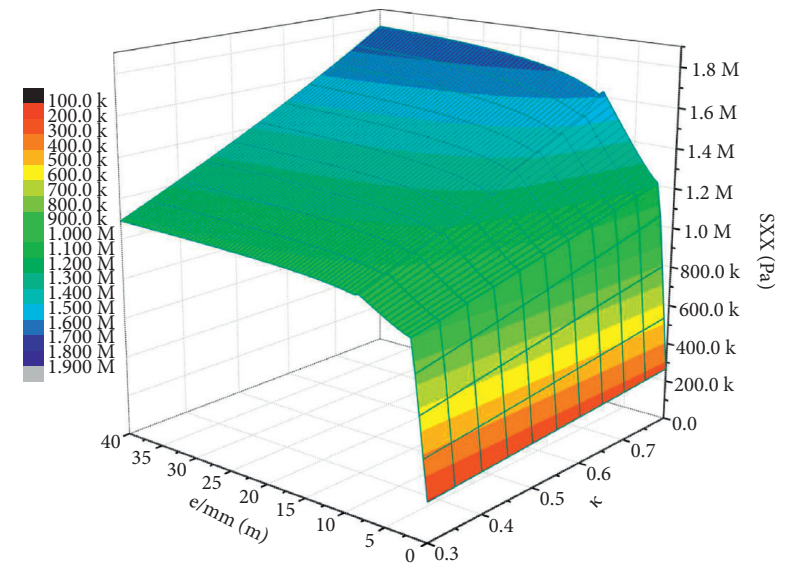

(e)

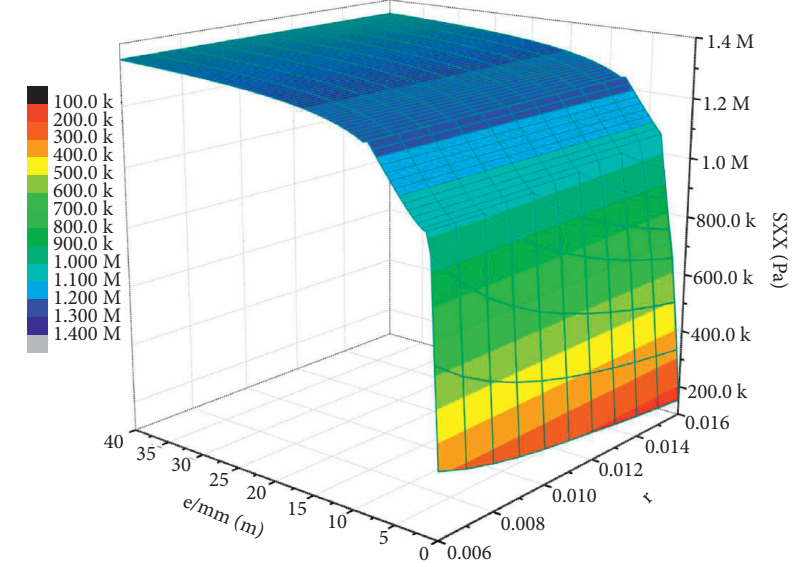

(b)

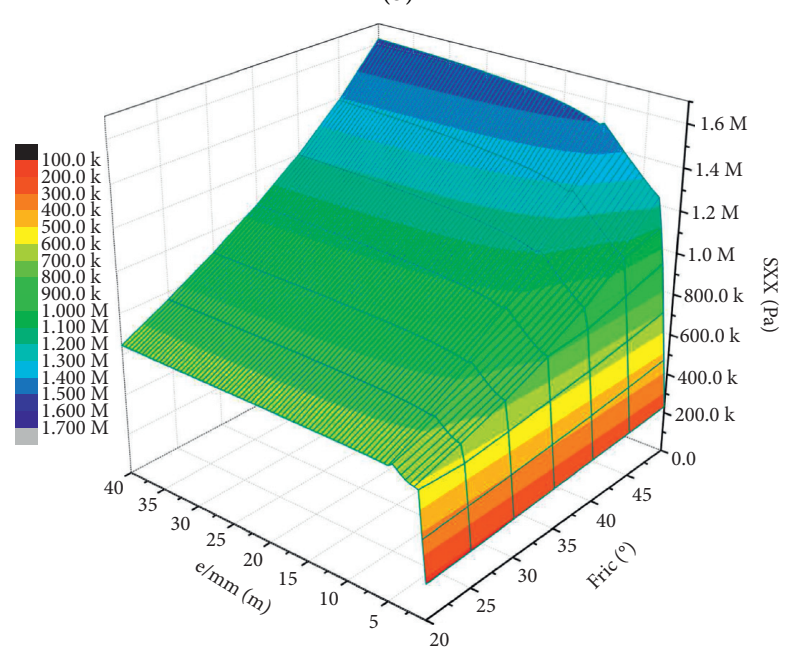

(d)

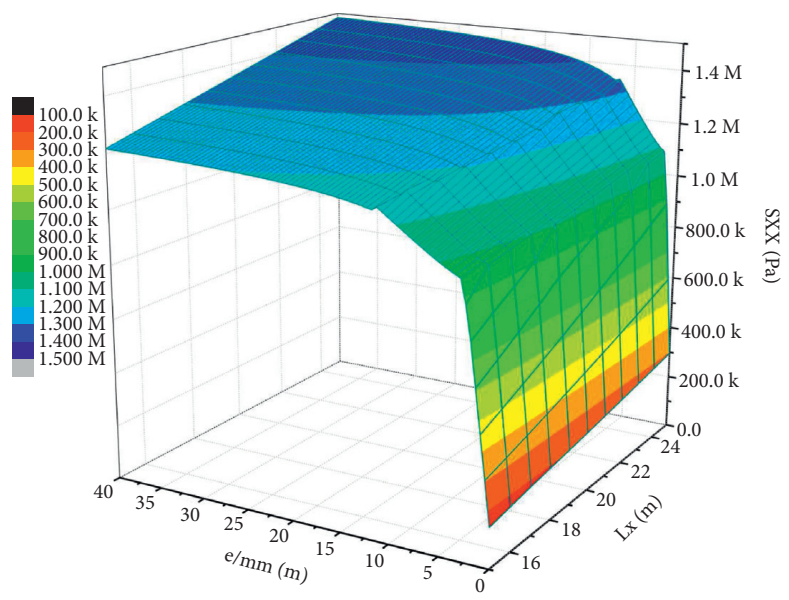

(f)

Figure 9: Continued. 


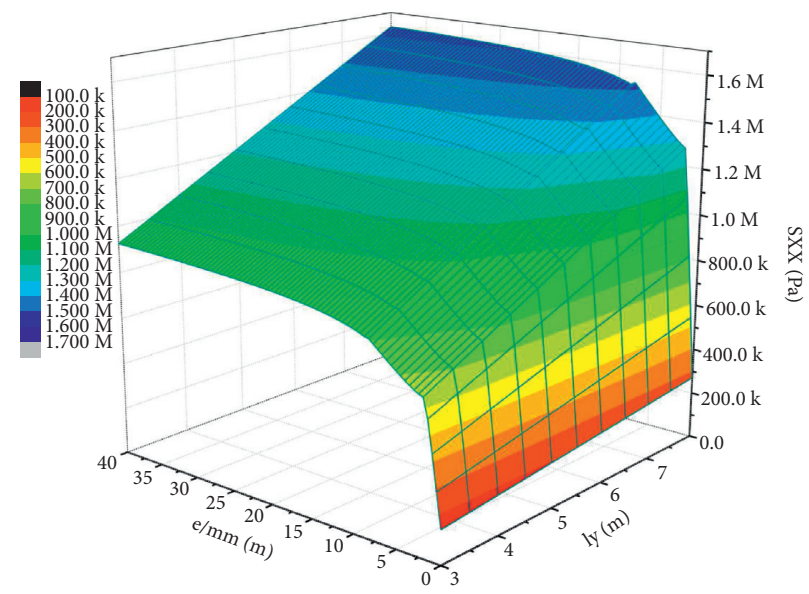

(g)

FIGURE 9: Influences of soil and building parameters on additional stress. (a) Shear modulus. (b) Soil ultimate shear strain. (c) Soil cohesion. (d) Soil internal friction. (e) Interface reduction coefficient. (f) Longitudinal wall length. (g) Transverse wall length.

building foundation wall, the less susceptible the building is to surface horizontal strain.

5.2.6. Length of Building's Longitudinal Wall. As illustrated in Figure 9(f), the extreme value of additional stress increases nearly in direct proportion with an increase in the length of the longitudinal wall before the horizontal strain value reaches the first abrupt point. After reaching the first abrupt point, the increase rate of additional stress decreases. When the length of the longitudinal wall is $15 \mathrm{~m}$, the extreme value of horizontal strain is $11 \mathrm{~mm} / \mathrm{m}$ and that of stress is 1.1 $\mathrm{MPa}$. When the length of the longitudinal wall increases to $24 \mathrm{~m}$, the extreme value of horizontal strain is $6 \mathrm{~mm} / \mathrm{m}$ and that of stress is $1.3 \mathrm{MPa}$. Therefore, an increase in the length of the longitudinal wall increases additional stress inside the building, making the building more vulnerable to surface horizontal strain.

5.2.7. Length of Building's Transverse Wall. The length of the transverse wall considerably influences additional stress. As depicted in Figure 9(g), additional stress increases rapidly with an increase in transverse wall length. When the length of the transverse wall is $3 \mathrm{~m}$, the extreme value of additional internal stress is $0.8 \mathrm{MPa}$. After the length of the transverse wall increases to $5 \mathrm{~m}$, the extreme value of additional stress increases rapidly to $1.5 \mathrm{MPa}$. Therefore, the longer the transverse wall, the greater the influence of horizontal strain on the building.

\section{Building Protection Method}

The preceding analysis indicates that stress concentration in a building under the horizontal strain of the ground surface is the primary cause of its damage. From the aforementioned research, three major reasons affect the degree of stress concentration in a building: (a) degree of horizontal strain, (b) mechanical properties of the foundation soil, and (c) size of the building. The greater the surface horizontal strain of a building, the more serious the damage degree of the building. The methods of filling mining, strip mining, and coordinated mining can be adopted to reduce the degree of surface horizontal strain. The higher the strength of the soil, the stronger the degree of stress concentration inside the building. Therefore, building foundation soil can be softened during the surface deformation process to reduce the damage brought by surface horizontal strain to a building. The larger the building, the more significant the effect. Deformation joints can be set at the middle of a large building to reduce the size of a single building, and consequently, decrease the effect of horizontal strain on the building.

\section{Discussion}

In the current study, a building is simplified into a strip structure, and the interaction between the soil and the building under horizontal strain is analyzed theoretically. The results show that the interactions between the soil and the building under the influence of surface horizontal strain are primarily interface contact force and Earth pressure, and their synergistic force causes tensile or compressive damage to buildings. Only a few scholars have simplified surface buildings into strip structures to discuss soil-structure interaction under surface deformation. El Kahi et al. [22] regarded a building as a strip, discussed the uncertainty when ground movement propagates to the structure, and identified the parameters of structural safety for evaluating building damage caused by ground movement. Son and Cording [23] considered a building a simple rectangle and proposed an assessment method for building damage based on 3D distorted structural units from the $2 \mathrm{D}$ strain state of a building caused by surface subsidence. In the current work, contact between the building foundation and the soil is studied, and the transmission and distribution of additional stress force are calculated, providing a reference for the possibility assessment of building damage. Giardina et al. [24], Ritter et al. [25], and 
Deck and Singh [26] discussed the harmful effects of bending deformation caused by surface subsidence on buildings; they examined the transmission of deformation between the soil and the structure through theoretical analysis and numerical simulation. However, surface subsidence will not only cause surface bending, but will also result in the horizontal strain of the surface. Buildings with a strip foundation are incapable of resisting tensile deformation, and thus, they should be studied extensively. By analyzing the internal interaction between the soil and the building foundation, the current study establishes a theoretical calculation model of the internal stress distribution of the building foundation under horizontal ground deformation. This model exhibits certain significance in building protection against horizontal ground deformation. However, considering the limit for the length of this article, the following problems are exhibited in this study. On the one hand, the foundation of a building is regarded as rigid, and its deformation will change the mutual influence between the soil and the foundation; thus, the calculation results may present certain deviations. On the other hand, this work only discusses the influence of horizontal ground deformation on buildings and does not consider the synergistic influences of other types of ground deformation (e.g., ground tilt) and curvature on buildings. This topic is one of the future research directions of the author.

\section{Conclusion}

With the effect of surface horizontal strain, additional horizontal stress caused by the interaction between the soil and the foundation of a building is the primary cause of building damage. In accordance with theories of interface contact and Earth pressure based on ultimate shear strain, a theoretical calculation model of the relationship between the horizontal strain value and additional stress inside a building foundation is established.

The model calculation indicates that under the action of surface horizontal strain, additional horizontal stress inside the foundation is the largest at the middle of the longitudinal wall and the smallest on both sides of the wall. Moreover, the decreasing speed increases from the middle to both sides of the wall. Additional stress at the middle of the longitudinal wall increases gradually with an increase in surface horizontal strain. In this process, an increase in additional stress results in two abrupt changes. After the second abrupt change, the growth rate of additional stress rapidly decreases and then gradually reaches its maximum value.

Through the analysis of the influences of soil and building parameters on additional horizontal stress, the following conclusions are drawn:

(a) Soil mechanical parameters and building characteristics exert certain influences on the variation characteristics of additional stress in a building foundation under different horizontal strain values.

(b) When protecting buildings affected by coal mining, not only the amount of surface deformation can be controlled, but building protection can also be achieved by improving the design of buildings or replacing the foundation soil.

\section{Data Availability}

All data, models, and codes generated or used during the study are included within this article.

\section{Disclosure}

This work has been presented as preprint in "Research Square.”

\section{Conflicts of Interest}

The authors declare that they have no conflicts of interest regarding the publication of this paper.

\section{Acknowledgments}

This work was funded by the University-Level Key Projects of Anhui University of Science and Technology (Grant no. xjzd2020-13), National Natural Science Foundation of China (Grant nos. 52104172, 51804301, 51674249, and 51904008), the Natural Science Foundation of Anhui Province (Grant nos. BK20180661 and 2108085Y20), and the Key Research and Development Projects in Anhui Province (Grant no. 201904bl1020015).

\section{References}

[1] L. Nie, M. Zhang, and H. Jian, "Analysis of surface subsidence mechanism and regularity under the influence of seism and fault," Natural Hazards, vol. 66, no. 2, pp. 773-780, 2013.

[2] Ş. Düzgün, C. Künzer, and C. Özgen Karacan, "Applications of remote sensing and GIS for monitoring of coal fires, mine subsidence, environmental impacts of coal-mine closure and reclamation," International Journal of Coal Geology, vol. 86, no. 1, pp. 1-2, 2011.

[3] X. Zhu, G. Guo, J. Zha, T. Chen, Q. Fang, and X. Yang, "Surface dynamic subsidence prediction model of solid backfill mining," Environmental Earth Sciences, vol. 75, no. 12, p. 1007, 2016a.

[4] B. Basmaji, O. Deck, and M. Al Heib, "Analytical model to predict building deflections induced by ground movements," European Journal of Environmental and Civil Engineering, vol. 23, no. 3, pp. 409-431, 2019.

[5] M. Son, "Response analysis of nearby structures to tunnelinginduced ground movements in sandy soils," Tunnelling and Underground Space Technology, vol. 48, pp. 156-169, 2015.

[6] J. Fu, Z. Yu, S. Wang, and J. Yang, "Numerical analysis of framed building response to tunnelling induced ground movements," Engineering Structures, vol. 158, pp. 43-66, 2018.

[7] C.-Y. Ou, F. Teng, and C.-W. Li, "A simplified estimation of excavation-induced ground movements for adjacent building damage potential assessment," Tunnelling and Underground Space Technology, vol. 106, Article ID 103561, 2020.

[8] X. Diao, K. Wu, D. Zhou, J. Wang, Z. Duan, and Z. Yu, "Combining subsidence theory and slope stability analysis method for building damage assessment in mountainous mining subsidence regions," PLoS ONE, vol. 14, no. 2, Article ID e0210021, 2019. 
[9] X. Lian and H. Dai, "Mapping the degree of damage to houses of paifang village, anhui, China, caused by underground coal extraction," Environmental Earth Sciences, vol. 75, no. 3, pp. 1-11, 2016.

[10] H. Akcin, "A gis-based building risk assessment for the subsidence due to undercity coal mining activities in zonguldak, Turkey," Arabian Journal of Geosciences, vol. 14, no. 5, 2021.

[11] X. Liu, G. Guo, and H. Li, "Study on damage of shallow foundation building caused by surface curvature deformation in coal mining area," KSCE Journal of Civil Engineering, vol. 23, no. 3, 2019.

[12] N. Kadiyan, R. S. Chatterjee, P. Pranjal et al., "Assessment of groundwater depletion-induced land subsidence and characterisation of damaging cracks on houses: a case study in Mohali-Chandigarh area, India," Bulletin of Engineering Geology and the Environment, vol. 80, no. 4, pp. 3217-3231, 2021.

[13] B. Eeka, A. Od, B. Mk, A. Rm, and B. Pr, "A new simplified meta-model to evaluate the transmission of ground movements to structures integrating the elastoplastic soil behavior sciencedirect," Structures, vol. 23, pp. 324-334, 2020.

[14] E. El Kahi, O. Deck, M. Khouri, R. Mehdizadeh, and P. Rahme, "Influence of geometrical uncertainties of analytical modelling on the evaluation of building deflections induced by ground movements," European Journal of Environmental and Civil Engineering, pp. 1-15, 2020.

[15] S. Moosazadeh, E. Namazi, H. Aghababaei, A. Marto, H. Mohamad, and M. Hajihassani, "Prediction of building damage induced by tunnelling through an optimized artificial neural network," Engineering with Computers, vol. 35, no. 2, pp. 579-591, 2019.

[16] R. L. Hu, Z. Q. Yue, L. C. Wang, and S. J. Wang, "Review on current status and challenging issues of land subsidence in China," Engineering Geology, vol. 76, no. 1-2, pp. 65-77, 2004.

[17] G. He, G. Ling, and L. Yang, Mining Subsidence, China University of Mining and Technology Press, Xuzhou, China, 1991, in Chinese.

[18] X. Zhu, G. Guo, J. Zha, T. Chen, Q. Fang, and X. Yang, "Surface dynamic subsidence prediction model of solid backfill mining," Environmental Earth Sciences, vol. 75, no. 6, pp. 1-9, 2016.

[19] K. Terzaghi, R. B. Peck, and G. Mesri, Soil Mechanics in Engineering Practice, John Wiley \& Sons, New York, NY, USA, 1996.

[20] T. Xie, Q. Luo, and L. Zhang, "Calculation of wall displacement to reach active or passive earth pressure state," Rock and Soil Mechanics, vol. 39, no. 5, pp. 1682-1690, 2018.

[21] P. Wilson, Large Scale Passive Force-Displacement and Dynamic Earth Pressure Experiments and Simulations, University of California, San Diego, CA, USA, 2009.

[22] E. El Kahi, O. Deck, M. Khouri, R. Mehdizadeh, and P. Rahme, "Simplified probabilistic evaluation of the variability of soil-structure interaction parameters on the elastic transmission of ground movements," Engineering Structures, vol. 213, Article ID 110554, 2020b.

[23] M. Son and E. J. Cording, "Estimation of building damage in a $3 \mathrm{D}$ distorting structure to tunnel and underground excavation-induced ground movements," Tunnelling and Underground Space Technology, vol. 97, Article ID 103222, 2020.

[24] G. Giardina, M. J. DeJong, B. Chalmers, B. Ormond, and R. J. Mair, "A comparison of current analytical methods for predicting soil-structure interaction due to tunnelling," Tunnelling and Underground Space Technology, vol. 79, pp. 319-335, 2018.
[25] S. Ritter, G. Giardina, M. J. DeJong, and R. J. Mair, "Influence of building characteristics on tunnelling-induced ground movements," Géotechnique, vol. 67, no. 10, pp. 926-937, 2017.

[26] O. Deck and A. Singh, "Analytical model for the prediction of building deflections induced by ground movements," International Journal for Numerical and Analytical Methods in Geomechanics, vol. 36, no. 1, pp. 62-84, 2012. 